\title{
Posterior malleol kırıklarında güncel yaklaşımlar
}

\author{
Current concepts in posterior malleol fractures
}

\author{
Murat Köken, Ertuğrul Akşahin, Levent Çelebi
}

Özel Medical Park Hastanesi, Ankara

\begin{abstract}
Posterior malleol kırıkları, genellikle rotasyonel ayak bilek yaralanmaları sonrasında hastaneye başvuran hastaların azımsanmayacak kısmında görülmektedir. Büyük kısmı trimalleoler kırıklara eşlik etmektedir. Posterior malleol, ayak bilek rotasyonel stabilitesi ve sindezmoz kompleksi stabilitesi için önemli bir yapıdır. Bu nedenle trimalleolar kırıkların tedavisi önemlidir; uygun şekilde yapılmazsa prognoz kötüleşmektedir. Posterior malleol kırıklarının tanı ve tedavisine yönelik artan ilgi ve farkındalığa karşın hala cevap aranan birçok soru bulunmaktadır. Posterior malleol kırıklarının morfolojisinin çok çeşitli olması nedeniyle, kolaylıkla tanı konması zordur. Tanı, sınıflama ve tedavi seçiminde tartışmalar devam etmektedir. Güncel yaklaşımda fikir birliğine varılan nadir konulardan biri bilgisayarlı tomografi (BT) ve 3B-BT değerlendirmesinin tanı ve tedavi planlamasında çok önemli olduğudur. Güncel yaklaşımlarda, tibiofibular mortisin stabilitesi ve distal fibulanın fibular çentik içinde uygun redüksiyonu, tedavi seçiminde belirleyici olmaya başlamıştır. Ayak bileği kırıkları tedavisinde, ayak bileğinin kemik ve bağ dokular yoluyla stabilitesi sağlanan kompleks bir eklem olduğu unutulmamalı, tedavi planlamasında tüm ayrıntılara gerekli önem verilmelidir.
\end{abstract}

Anahtar sözcükler: posterior malleol; ayak bileği; kırık; cerrahi tedavi
Posterior malleolus fractures are usually seen in the substantial portion of patients admitted to the hospital after rotational ankle injuries. The majority of these injuries accompanies trimalleolar fractures. Posterior malleolus is an important structure for the rotational stability of the ankle joint as well as for the syndesmosis complex stability. Therefore it is important to treat trimalleolar fractures properly, otherwise the prognosis will be worse. Despite the increased interest and awareness in diagnosis and treatment of posterior malleolus fracture, there are still many controversial issues. The posterior malleolus fractures are difficult to diagnose because of the wide variety of the morphology. The debate for preferences in diagnosis, classification and treatment is ongoing. One of the topics which provided consensus is the importance of using computerized tomography (CT) and $3 \mathrm{D}-\mathrm{CT}$ in planning diagnosis and treatment. In current approaches, the stability of the distal tibiofibular mortise and the appropriate reduction of the distal fibula in fibular notch has begun to be important parameters for the treatment choice. In the treatment of ankle fractures, it should be noted that the stability of the ankle joint is provided by both soft tissue and bone complex, and careful consideration should be given to all details while planning treatment.

Key words: posterior malleolus; ankle; fracture; surgical treatment osterior malleol (PM) kırıkları, sanılanın aksine yaygın kırıklardır ve tüm ayak bilek kırıklarının \%7-44'ünü oluşturmaktadır. ${ }^{[1,2]}$ Genellikle oluş nedeni rotasyonel ayak bilek travmalarıdır. Büyük kısmı trimalleolar kırıklara eşlik etmekle birlikte, izole PM kırıkları da \%1 oranında görülmektedir. ${ }^{[3]}$ Lauge-Hansen sınıflamasında, hem supinasyon hem de pronasyon tipi yaralanmalarda sık görülmektedir. ${ }^{[4]}$ İzole kırıklar genellikle aksiyel yüklenme ve plantar fleksiyonda yaralanmalar sonrasında görülmektedir. PM kırıklarına olan ilgi ve farkındalığın artmasına karşın, hala cevap aranan birçok soru bulunmaktadır. Tanı, sınıflama ve tedavi seçiminde tartışmalar devam etmektedir.

PM kırıklarının morfolojisi, posterolateral küçük kopma kırığından deplase büyük kırık bir parçaya kadar değişkenlik göstermektedir. ${ }^{[5-8]} \mathrm{PM}$ ve bağlar; tibiotalar yük transferi, ayak bileği rotasyonel stabilitesi ve sindezmoz kompleksi stabilitesi için önem taşımaktadır. Ogilvie-Harris ve arkadaşları ${ }^{[9]}$ yaptıkları kadavra çalışmasında, PM'den başlayarak fibula distalinde sonlanan posterior inferior tibiofibular bağın (PiTFB) sindezmotik stabilitenin \%42`sini sağladığını

- İletişim adresi: Uzman Dr. Murat Köken, Özel Medical Park Ankara Hastanesi, Kent Koop. Mah. 1868. Sok. No:15 Batıkent, Yenimahalle, Ankara Tel: 0312 - 6668000 e-posta: murat.koken@medicalpark.com.tr

- Geliş tarihi: 3 Mayıs $2016 \quad$ Kabul tarihi: 3 Mayıs 2016 
göstermişlerdir. PM kırıklarında bu sindezmotik katkı bozulmaktadır. Kemik ve ligamentöz stabilitenin kaybı sonrası instabil bir ayak bileğinde ortaya çıkan fizyolojik olmayan hareketler, ayak bileğinde dejenerasyon gelişmesi için zemin hazırlamaktadır. Ayak bilek kırıklarında salt posterior fragmanın bulunması dahi prognozu kötü yönde etkilemektedir. ${ }^{[10-13]}$

Literatürde, kırıklı-çıkı̆̆ı olan ayak bilek yaralanmalarında distal tibia arka kenarında oluşan kırık için "Volkmannsches Dreieck" (Volkmann üçgeni) tanımı ilk olarak 1828 yılında Henry Earle tarafindan kullanılmış ${ }^{[14]}$ ve genel olarak kabul görmüştür. ${ }^{[15-17]}$ Aynı tanım 1926 'da Karl Ludloff ${ }^{18]}$ ve 1931 yılında Fritz Felsenreich ${ }^{[19]}$ tarafindan "Volkman Dreieck" olarak tekrar kullanılmıştır. Distal tibia posterior kenarındaki kırığın ayrıntılı tanımlaması ve posterior malleol olarak adlandırılması, 1911 yılında Etienne Destot'un kitabında görülmektedir ${ }^{20]}$. Frederick Jay Cotton, daha sonra kendi ismiyle de anılacak olan tanımında, bimalleolar kırık ve eşlik eden distal tibia arka kenar kırığı olarak tanımlamıştır. ${ }^{[21]}$ Ancak ,1932'de Melvin Henderson bu yaralanmayı trimalleolar kırık olarak tanımlamışırı. ${ }^{[22]}$ 1940 yılında Nelson ve Jensen ${ }^{[23]}$ distal tibia arka kenar kırıklarını eklem yüzeyini üçte birden fazla etkileyen ve üçte birden az etkileyen kırıklar olarak sınıflamışlar ve günümüzde de birçok cerrah tarafından olarak kabul gören klasik “üçte bir kuralı”nı ve posteromediyal yaklaşımla vida tespitini önermişlerdir. ${ }^{[24]}$

\section{TANI}

Ayak bileği yaralanmasıyla başvuran hastaların ilk değerlendirmesinde istenmesi gereken tetkikler; gerçek ön-arka, tam yan ve mortis grafileridir. PM kırıkları lateral radyografilerde saptanabilmekle (Şekil 1) birlikte, AP grafilerde mediyal malleol çift kontur görüntüsü PM kırığı için uyarıcı olmalıdır. ${ }^{[25,26]}$ Kırığın gerçek boyutu ve geometrisinin tespitinde ise en geçerli yöntem bilgisayarlı tomografi (BT)'dir. ${ }^{[7,8]}$ Transvers ve sagittal plan BT görüntüleri, üç boyutlu BT rekonstrüksiyon (3D-BT) ile birlikte değerlendirilmelidir (Şekil 2). Manyetik rezonans görüntülemenin rutin uygulamada yeri oldukça kısıtlıdır. ${ }^{[5,7,8]}$

\section{SINIFLAMA}

Tarihsel önemi olan birkaç sınıflama olsa da, günümüzde BT kullanılarak yapılmış, tedavi seçiminde de yardımcı olan güncel iki sınıflandırma daha fazla tercih edilmektedir. Haraguchi ve arkadaşlarının BT kullanarak yaptıkları sınıflamada üç tip tanımlanmıştır: [7]

1. Posterolateral oblik tip (\%67)

2. Mediyal uzanımlı tip (\%19)

\section{Küçük kabuk tip (\%14)}

Bartonícek ve Rammelt 2015 yılında 3B-BT görüntüleri kullanılarak yaptıkları güncel sınıflamada ise dört tip tanımlamışlardır: ${ }^{[8]}$

Tip 1: İntakt fibular çentik ile beraber ekstra-insisural kırık (\%8).

Tip 2: Fibular çentiğin $1 / 4-1 / 3$ kırığı ile birlikte intra-insisural posterolateral kırık (\%52).

Tip 3: Fibular çentiğin posterior parçasının lateralde olduğu, intra-insisural posteromediyal iki parçalı kırık (\%28).

Tip 4: Fibular çentiğin arka yarısını içeren büyük posterolateral üçgen kırık (\%9).

İlave olarak yukarıda belirtilen gruplara dahil edilemeyen, düzensiz ve osteoporotik PM kırıkları toplu olarak Tip 5 olarak adlandırılmaktadır.

\section{TEDAVi}

İzole, ayrılmamış PM kırıklarında konservatif tedavi tercih edilmelidir. Tarihsel olarak PM cerrahi tespiti için, ayak bilek instabilitesi bulunması endikasyon olarak kabul edilmekteydi. Daha sonra dikkatler eklem uyumuna ve tibia pilon eklem yüzeyinin restorasyonuna odaklandı. Son zamanlarda da tibiofibular mortisin stabilitesi ve distal fibulanın fibular çentik içinde uygun redüksiyonu, tedavi seçiminde belirleyici olmaya başladı.

Uzun zaman boyunca, PM kırık parçasının boyu ve deplasmanı cerrahi endikasyonları belirlemekteydi. Lateral grafideki eklem yüzeyinin üçte bir veya dörtte birini içeren kırıklar ve $2 \mathrm{~mm}$ 'den fazla ayrılma, kritik kabul edilmekteydi. Ancak, oblik ve düzensiz kırıklarda tedavi kararını vermek zordu.

Güncel yaklaşım olarak PM'nin anatomik redüksiyonu ile aşağıdaki parametrelerin kazanımı amaçlanmaktadır:

- Tibia pilonun eklem yüzünü orijinal boyutunda restore ederek, ayak bileği posterior stabilitesinin sağlanması.

- PiTFB'ın restorasyonu ile ayak bilek mortisinin stabilitesinin sağlanması.

- Weber tip C ve Maisonneuve kırıkları gibi yüksek fibular kırıklarda distal fibula redüksiyonunu sınırlandıran/engelleyen fibular çentiğin redükte edilmesi.

Bartonícek ve Rammelt'in ${ }^{[8]}$ sınıflaması ise tedaviye karar vermek için kullanılabilecek güncel sınıflamadır:

- Tip 1 (ekstra-insisural): konservatif, non-operatif. 


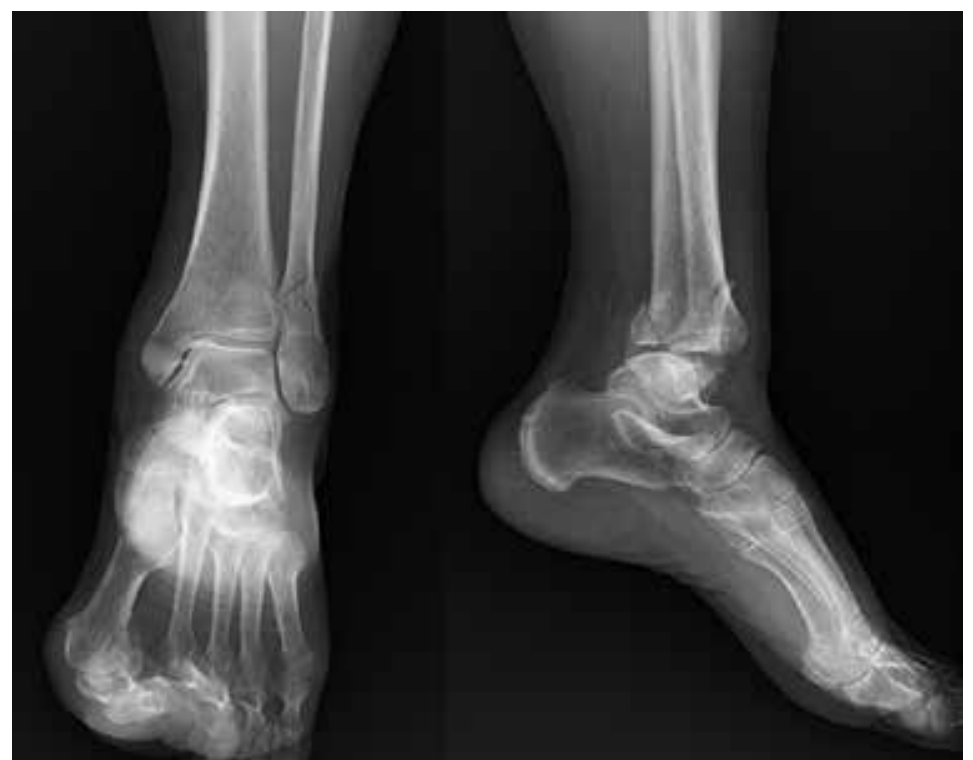

Şekil 1. Sol ayak bileği ön-arka ve lateral grafilerde posterior malleol kırığının görünümü.

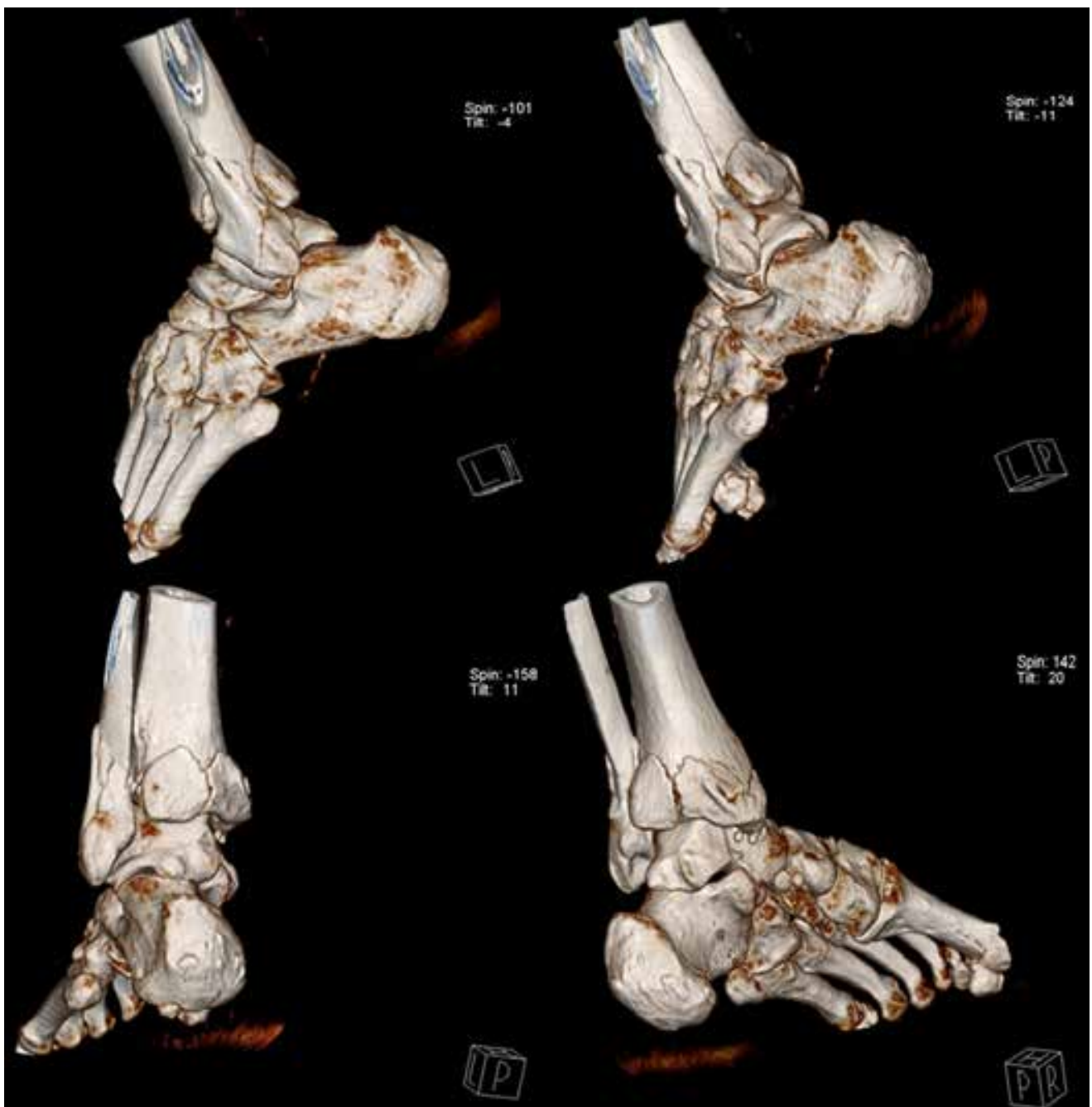

Şekil 2. Posterior malleol kırığının 3B-BT rekonstrüksiyon görüntüleri. 
- Tip 2 (posterolateral): kırık parçanın boyutu, impakte olan interkalar parça bulunması ve fibula kırığının tipi cerrahi için endikasyonda önemlidir.

- Tip 3 (iki parçalı): tibiotalar stabilizasyon kaybı, etkilenen eklem yüzeyi büyüklüğü ve fibular çentik ile ilişki cerrahi endikasyonudur. Açık redüksiyon ve içten tespit ile eklem bütünlüğü ve restorasyonu önerilir.

- Tip 4 (büyük üçgen): ayak bileği instabilitesi ve eklemde kopan büyük parça nedeniyle açık redüksiyon ve içten tespit her zaman önerilir.

\section{CERRAHI YÖNTEMLER VE TESPIT TEKNIKLERi}

PM'nin açık redüksiyon ve içten tespiti direkt ve indirekt tekniklerle yapılabilir:

- İndirekt redüksiyon ve anterior yaklaşımla vida tespiti.

- Transfibular redüksiyon ve anterior veya posterior yaklaşımla vida tespit.

- Direkt redüksiyon ve posterolateral yaklaşımla tespit.

- Direkt redüksiyon ve posteromediyal yaklaşımla tespit.

Cerrahi yöntemin seçiminde PM kırığı ile birlikte olan diğer kırıklar ve yaralanmalar da birlikte değerlendirilmelidir.

\section{İndirekt Redüksiyon ve Anteriordan Posteriora Tespit}

Klasik olarak en popüler olan yaklaşımdır. Tipik olarak lateral ve mediyal malleolün içten tespitini takiben, ayak bileği dorsifleksiyona alınarak ve posterior parçanın redüksiyonu sağlanarak perkütan Kirschner teli (K-teli) veya kemik pensi ile geçici tespiti yapılır. íki adet kansellöz kompresyon vidası veya imkan varsa kanüllü vida ile kalıcı tespit yapılır. Büyük, tek parçalı kırıklar için uygun bir yaklaşımdır (Şekil 3). Küçük kırıklarda kırığın katı tespiti ve kompresyonu zor olacağından önerilmemektedir.

\section{Transfibular Redüksiyon ve Anterior veya Posterior Yaklaşımla Vida Tespiti}

Transfibular teknikte tibia plafondunu görüp değerlendirmek zor olduğundan, bu çok sık kullanılan bir yöntem değildir. Fibula kırığının uzun oblik olduğu Weber Tip B kırıklarda, kırık hattının dış rotasyon manevrası ile distale deplase edilmesi ile fibular çentik ve tibia posterior kenarını görmek mümkün olmaktadır. PM redükte edilerek K-teli ile geçici tespiti takiben, anteriordan laterale vida ile tespit yapılabilmektedir. Kim ve arkadaşları, bu tekniği modifiye ederek posteriordan anteriora vida ile tespiti önermektedirler.

\section{Direkt Redüksiyon ve Posterolateral Yaklaşımla Tespit}

Bu yaklaşım, tibia arka kenar kırıkları ve distal fibula kırıklarına aynı anda ulaşım ve müdahale imkanı vermektedir. Tip 2 ve Tip 4 kırıkların tedavisinde önerilen yöntemdir. Özellikle PM parçasının küçük olduğu ve indirekt olarak redükte edilemeyen kırıklarda kullanışı bir yöntemdir. Hastaya pron veya semipron pozisyon verilerek, distal fibula arka kenarından lateral malleol tepesine kadar uzunlamasına kesi yapılır ve lateral malleol tepesinden hafif bir kavisle anteriora dönülür. Alternatif olarak, kesi distal fibula ve Aşil tendonu ortasından klasik posterolateral yaklaşım (Gallie yaklaşımı) kullanılarak da yapılabilir. Sural sinirin korunmasına dikkat edilmelidir. Peroneal fasya geçilerek aynı aralıktan peroneal tendonlar anteriora alınmalıdır. Takiben, fleksor hallucis longus kası (FHL) derin fasyasında uzunlamasına kesi yapılır. FHL tendonu mediyale alınır; böylece derin posterolateral nörovasküler yapılar korunarak, distal tibia arka kenarını görmek mümkün olur. Posterolateral kırık parça, PITFB'a zarar vermeden nazikçe mobilize edilir. Kırık uçlarının temizlenmesini takiben redükte edilerek, geçici tespit K-telleri ile yapılır. Redüksiyon ve eklem yüzü uyumu skopi ile kontrol edilmeli ve uygun redüksiyon sağlanmış ise kalıcı tespit $3,5 \mathrm{~mm}$ 'lik pullu vidalar veya uygun şekilli plak ile yapılmalıdır. Maksimum stabilite için, distale konulan vidanın eklem yüzeyine mümkün olduğunca yakın olması ve tibia anterior korteksine kadar ulaşması gerekmektedir. Takiben, distal fibula kırığı redüksiyonu ve tespiti yapılmalıdır. Mediyal malleol kırığı da mevcutsa, mediyal kesiyi takiben redükte edilerek uygun tespit yapılmalıdır.

\section{Direkt Redüksiyon ve Posteromediyal Yaklaşımla Tespit}

Bu yaklaşım ise, tek kesi ile tibia arka kenar kırıkları ve mediyal malleol kırıklarına aynı anda ulaşım ve müdahale imkanı vermektedir. Bartonićek ve Rammelt Tip 3 PM kırıklarıyla beraber posteromediyal parça içeren mediyal malleol kırıkları için kullanışlıdır. Hastaya supin pozisyon verilir. Kesi mediyal malleol distal arka kenarı boyunca malleol tepesine kadar uzunlamasına yapılır ve hafif bir kavis ile anteriora yönlendirilir. Krural fasya geçilerek tibialis posterior tendonu ve fleksor digitorum longus tendonu mobilize edilerek anteriora alınır ve posterior tüberkülün görülmesi sağlanır. Posterior nörovasküler yapılara dikkat etmek gerekmektedir. 

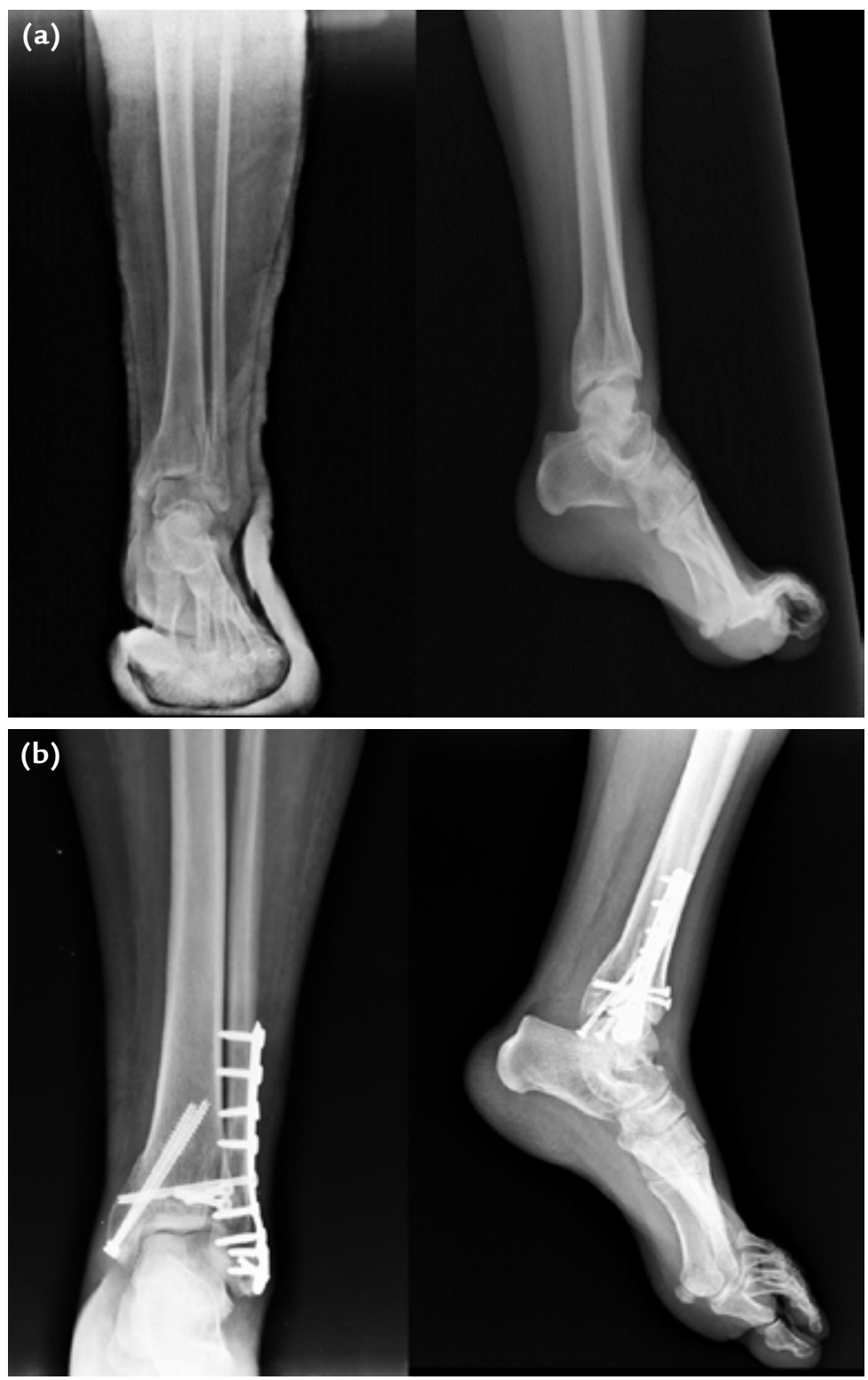

Şekil 3. a, b. Trimalleolar kırık ön-arka ve lateral grafiler (a). İndirekt redüksiyonu takiben anteriordan posteriora vida tespiti (b).

\section{PROGNOZ VE KOMPLIKASYONLAR}

Trimalleolar kırıklar, bimalleolar kırıklardan daha kötü prognozludur. Posterior kırık parça küçük dahi olsa klinik sonuçları kötü yönde etkilemektedir. Nelson ve Jensen, cerrahi tespit uyguladıkları eklemin üçte birini içeren, büyük PM parçası olan üç hastada iyi, buna karşın cerrahi tespit uygulamadıkları yine büyük PM kırıklı beş hastada kötü sonuçlar aldıklarını bildirmişlerdir. ${ }^{[23]}$ Jaskulka ve arkadaşları, büyük PM kırıklarında redüksiyon ve içten tespit sonuçlarının, cerrahi olmayan yöntem ile karşılaştırıldığında daha iyi olduğunu tespit etmişlerdir. ${ }^{[10]}$ Anatomik olmayan redüksiyon ve içten tespit yapılan PM kırıklarının sonuçları ise, cerrahi uygulanmayan olgularla karşılaştırıldığında daha kötü olarak bulunmuştur. ${ }^{[12]}$ Malunion ve nonunion bildirilen az sayıda olgu mevcuttur. Ayak bileği stabilitesinin sağlanamadığı durumlarda, ayak bilek füzyonu kurtarıcı cerrahi olarak düşünülmelidir. ${ }^{[26]}$

Sonuç olarak, literatürdeki değerlendirmeler incelendiğinde, büyük bir çoğunun geriye dönük oldukları, tanı ve tedavide bir standardın olmadığı görülmektedir. Bu nedenle, PM kırıkları tanı ve tedavisinde kanıta 
dayalı rehberler sunmak günümüzdeki verilerle zor görünmektedir. Güncel yaklaşımda fikir birliğine varılan nadir konulardan biri, BT ve 3B-BT ile değerlendirmenin, tanı ve tedavi planlamasında çok önemli olduğudur. PM kırıklarının ayak bileği sindezmoz stabilitesinde önemli olduğu bilgisi ve iyi eklem yüzeyi restorasyonu sağlanan anatomik redüksiyonun sonuçlarının iyi olması, birçok hekimi cerrahi yönünde cesaretlendirmektedir. Sayıca daha fazla olgu içeren orta ve uzun dönem sonuçlar ortaya çıktıkça, daha fazla konuda fikir birliğine ulaşılacağı aşikardır. Ayak bileği kırıkları tedavisinde, ayak bileğinin kemik ve bağ dokular yoluyla stabilitesi sağlanan kompleks bir eklem olduğu unutulmamalı, tedavi planlamasında tüm ayrıntılara gerekli önem verilmelidir.

\section{KAYNAKLAR}

1. Jaskulka RA, Ittner G, Schedl R. Fractures of the posterior tibial margin: their role in the prognosis of malleolar fractures. J Trauma 1989;29(11):1565-70.

2. Court-Brown CM, McBirnie J, Wilson G. Adult ankle fractures -an increasing problem? Acta Orthop Scand 1998;69(1):43-7.

3. Boggs LR. Isolated posterior malleolar fractures. Am J Emerg Med 1986;4(4):334-6.

4. Lauge-Hansen N. Fractures of the ankle: II. Combined experimental-surgical and experimental-roentgenologic investigations. Arch Surg 1950;60(5):957-85.

5. Müller ME, Nazarian S, Koch P, SchatzkerJ. The Comprehensive Classification of Long Bones. Berlin: Springer; 1987.

6. Heim UF. Trimalleoar fractures: late results after fixation of the posterior fragment. Orthopedics 1989;1288):1053-9.

7. Haraguchi $N$, Haruyama $\mathrm{H}$, Toga $\mathrm{H}$, Kato F. Pathoanatomy of posterior malleolar fractures of the ankle. J Bone Joint Surg Am 2006;88(5):1085-92.

8. BartoníćekJ, Rammelt S, Kostlivý K, Vaněček V, Klika D, Trešl I. Anatomy and classification of the posterior tibial fragment in ankle fractures. Arch Orthop Trauma Surg 2015;135(4):50516. Crossref

9. Ogilvie-Harris DJ, Reed SC, Hedman TP. Disruption of the ankle syndesmosis: biomechanical study of the ligamentous restraints. Arthroscopy 1994;10(5):558-60.
10. Jaskulka RA, Ittner G, Schedl R. Fractures of the posterior tibial margin: their role in the prognosis of malleolar fractures. J Trauma 1989;29(11):1565-70.

11. Leed HC, Ehrlich MG. Instability of the distal tibiofibular syndesmosis after bimalleolar and trimalleolar ankle fractures. J Bone Joint Surg Am 1984;66(4):490-503.

12. Tejwani NC, Pahk B, Egol AE. Effect of posterior malleolus fracture on outcome after unstable ankle fracture. J Trauma 2010;69(3):666-9. Crossref

13. Zenker $\mathrm{H}$. Nerlich $M$. Prognostic aspects in operated ankle fractures. Arch Orthop Trauma Surg 1982;100(4):237-41.

14. Earle H. Simple, succeeded by compound dislocation forwards, of the inferior extremity of the tibia, with fracture of its posterior edge: comminuted fracture of the fibula, amputation of the leg, and death. Lancet 1828-29;2:346-8.

15. Bartonícek J. Avulsed posterior edge of tibia Earle's or Volkmann's triangle? J Bone Joint Surg Br 2004;86(5):746-50.

16. Heim U. Indikation und Technik der Stabilisierung des hinteren Kantendreiecks nach Volkmann bei Malleolarfrakturen. Unfallheilkunde 1982;85L39)88-94.

17. Lauge N. Fractures of the ankle; analytic historic survey as the basis of new experimental, roentgenologic and clinical investigations. Arch Surg 1948;56(3):259-317.

18. Ludloff K. Zur Frage der Knöchelbrüche mit Herausprengung eines hinteren Volkmannschen Dreiecks. Zentralbl Chi 1926;53:390-1.

19. Felsenreich F. Untersuchung über die Pathologie des sogenannten Volkmannschen Dreiecks neben Richtlinien moderner Behandlung schwerer Luxationsfrakturen des oberen Sprunggelenkes. Arch Orthop Unfallchir 1931;29:491-529.

20. Destot E-A-J. Traumatisme du pied et rayons $\mathrm{X}$ : malléoles, astragale, calcanéum, avant-pied. Paris: Masson et Cie; 1911.

21. Cotton FJ. A new type of ankle fracture.JAMA 1915;64:318-21.

22. Henderson MS. Trimalleolar fractures of the ankle. J Surg Clin North Am 1932;12:867-72.

23. Nelson MC, Jensen NK. The treatment of trimalleolar fractures of the ankle. Surg Gynecol Obstet 1940;71:509-14.

24. Heim D. Der posteriore Malleolus bzw. das VolkmannDreieck. Unfallchirurg 2013;116:781-8.

25. Irwin TA, Lien J, Kadakia AR. Posterior malleolus fracture. J Am Acad Orthop Surg 2013;21(1):32-4. Crossref

26. Bartonícek J, Rammelt S, Tuček M, Nanka O. Posterior malleolar fracture of the ankle. Eur J Trauma Emerg Surg 2015;41(6):587-600. Crossref 